\title{
A POPULATION-BASED EVALUATION OF THE SPECIFIC RISKS FOR FIVE MAJOR CONGENITAL HEART DEFECTS IN RELATION TO ASSISTED REPRODUCTIVE TECHNOLOGIES
}

\author{
K. Tararbit ${ }^{1}$, N. Lelong ${ }^{1}$, A.-C. Thieulin ${ }^{1}$, L. Houyel ${ }^{2}$, D. Bonnet ${ }^{3}$, F. Goffinet ${ }^{1}$, B. Khoshnood ${ }^{1}$ \\ ${ }^{1}$ Inserm, UMR S 953, Recherche Epidémiologique sur la Santé Périnatale et la Santé des Femmes et des \\ Enfants, UPMC, Université Paris-6, Paris, ${ }^{2}$ Service de Chirurgie des Cardiopathies Congénitales, Hôpital \\ Marie Lannelongue, Le Plessis Robinson, ${ }^{3}$ Centre de Référence M3C-Necker, Université Paris Descartes, \\ Paris, France
}

Background and aims: Assisted Reproductive Technologies (ART) are associated with an increase in the overall risk of birth defects. Few studies have examined the specific risks for Congenital Heart Defects (CHD).We estimated the risk of Tetralogy of Fallot (TOF), Coarctation of the aorta, Transposition of great arteries, Hypoplastic left heart syndrome and Heterotaxy in relation to different methods of ART.

Methods: We used data from the Paris Registry of Congenital Malformations and a population-based cohort study of CHD on 1617 cases of CHD and 4009 malformed controls with no known associations with ART. ART included inductors of ovulation only, in vitro fertilization and intracytoplasmic sperm injection (ICSI).

Results: Exposure to ART was significantly higher for TOF than controls ( 6.8 vs. $3.5 \%, \mathrm{P}=0.001)$; this was not the case for the other four CHD. ART (all methods combined) were associated with a 2.5 -fold higher odds of TOF after adjustment for maternal characteristics, paternal age and year of birth (Adjusted OR 2.5, 95\% CI 1.6-4.1) with the highest risk associated with ICSI (Adjusted OR 3.2, 95\%CI 1.1-9.4). No statistically significant associations were found for the other CHD.

Conclusion: The higher risk of TOF in relation to ART (and particularly ICSI) may be due to a specific underlying mechanism, different from those of the other CHD studied, not yet fully unraveled. 